\title{
PENGARUSUTAMAAN GENDER DALAM PEMBANGUNAN PERTANIAN : KASUS PADA PELAKSANAAN PROGRAM FEATI DI KABUPATEN MAGELANG
}

\author{
Dian Maharso Yuwono \\ Balai Pengkajian Teknologi Pertanian (BPTP) Jawa Tengah \\ E-mail: dianmy@yahoo.com
}

\begin{abstract}
Efforts to improve the effectiveness and efficiency of utilization of agricultural resources in order to accelerate the increase in the welfare of farmers cannot be separated from the role of women in agricultural development. Gender mainstreaming in agricultural development is mandated by Presidential Decree No. 9 of 2000. This decree is a strategy to achieve gender equality in development. The gender aspects must be integrated in policy formulation and program activities from planning to evaluation. This paper aims to reveal the women role in the program implementation of Farmer Empowerment through Agricultural Technology and Information (FEATI) in Magelang District-Central Java that integrates gender mainstreaming.
\end{abstract}

Keywords: role, women, development, agriculture, FEATI

\section{PENDAHULUAN}

Berbagai hasil penelitian membuktikan bahwa perempuan menjadi bagian yang penting dari tenaga kerja di sektor pertanian, baik itu pada penyediaan sarana pertanian, budidaya tanaman dan ternak, pengolahan dan pascapanen, hingga pemasaran hasil pertanian. Hasil penelitian Sajogyo (1984) mendapatkan bahwa perempuan memberikan kontribusi yang besar dalam ekonomi masyarakat maupun dalam kehidupan keluarga. Safar (2006) menyampaikan bahwa apabila dilihat dari curahan waktu kerja rata-rata, perempuan sangat berperan dalam aktivitas pertanian, terutama pada sub sistem produksi (Mulyadi et al., 1993), dimana kontribusi perempuan pada kegiatan produksi pertanian tersebut masih dipengaruhi budaya, tipe agroekosistem, dan status sosial ekonomi rumah tangga.

Dominasi perempuan di sektor pertanian tersebut telah berlangsung lama dan dipandang sebagai sesuatu yang wajar. Memperhatikan peran sentral perempuan dalam kegiatan pertanian maka perempuan petani harus diberi kesempatan yang sama dengan laki-laki untuk memperoleh akses kepada lahan dan sumberdaya yang lain, seperti kredit, teknologi, dan pengetahuan (Wahyuni, 2007). Dengan demikian, upaya peningkatan efektivitas dan efesiensi pemanfaatan sumberdaya pertanian guna mengakselerasikan peningkatan kesejahteraan petani tidak dapat dipisahkan dengan peranan perempuan dalam pembangunan pertanian.

Terlepas dari kontribusinya dalam usahatani, umumnya perempuan petani adalah sumberdaya manusia yang masih diabaikan dalam program pembangunan pertanian. Kondisi ketertinggalan perempuan dapat menggambarkan dengan adanya ketidakadilan dan ketidaksetaraan antara laki-laki dan perempuan di Indonesia (Soemartoyo, 2002). Implementasi program pembangunan pertanian di tingkat desa menunjukkan akses laki-laki terhadap program pembangunan lebih besar dibanding perempuan (Hastuti, E.L., 2004a). Paradigma modernisasi dalam pelaksanaan pembangunan pertanian yang mengutamakan prinsip efisiensi, secara nyata telah mengakibatkan terjadinya berbagai perubahan pada masyarakat petani, baik struktur sosial, budaya dan politik terutama pada struktur ekonomi di perdesaan.

Alokasi sumberdaya pertanian terbukti tidak memberikan kesempatan yang sama berdasarkan gender. Pilihan dan partisipasi perempuan dalam proses pembangunan sangat terbatas, menyebabkan perempuan harus melalui banyak rintangan 


\section{Dian Maharso Yuwono: Pengarusutamaan Gender Dalam Pembangunan Pertanian ...}

untuk mendapatkan akses dan kontrol. Dalam rangka penyebarluasan teknologi baru, karena perilaku bias laki-laki, kecil kemungkinannya penyuluh pertanian untuk menempatkan perempuan sebagai target (Wijaya 1993). Hasil penelitian menunjukkan bahwa penerapan teknologi pertanian modern telah meminggirkan bahkan menghilangkan akses dan kontrol perempuan petani khususnya pada aspek budidaya. Proyek-proyek pembangunan tidak banyak melibatkan perempuan, sehingga dalam introduksi teknologi pertanian petani perempuan tidak memperoleh akses sebagaimana pada petani laki-laki (Hesti, R.W., 2012).

Berdasarkan hal tersebut, peningkatan peranan perempuan dalam pembangunan mendapat perhatian yang besar dari pemerintah, dimana upaya peningkatan status dan kedudukan perempuan dalam semua aspek pembangunan satatus dan kondisi perempuan dicantumkan sebagai isu lintas bidang pembangunan. Diterbitkannya Inpres Nomor 9 tahun 2000 yang mengamanatkan pengarusutamaan gender (PUG) atau gender mainstreming dalam pembangunan pertanian adalah strategi untuk mewujudkan kesetaraan dan keadilan gender dalam pembangunan, dimana aspek gender harus terintegrasi dalam perumusan kebijakan program dan kegiatan sejak perencanaan hingga evaluasi.

Salah satu program pembangunan pertanian yang mengintegrasikan aspek gender dalam pelaksanaannya adalah Program Pemberdayaan Petani melalui Teknologi dan Informasi Pertanian (P3TIP) atau Farmer Empowerment Through Agricultural Technology and Information (FEATI), yang diimpementasikan tahun 2007-2011 dan diperpanjang sampai dengan tahun 2012. Program FEATI bertujuan untuk meningkatkan produktivitas, pendapatan dan kesejahteraan petani melalui pemberdayaan keluarga petani dan organisasi petani dalam mengakses informasi, teknologi, modal dan sarana produksi untuk mengembangkan usaha agribisnis dan mengembangkan kemitraan dengan sektor swasta (Badan Pengembangan SDM Pertanian, 2007).

Program FEATI merupakan program berbantuan dari Bank Dunia berdasar Loan Agreement International Bank for Reconstruction and Development (IBRD) No.
7427-0-IND tanggal 13 Februari 2007 antara Pemerintah Indonesia dengan Bank Dunia dan Development Credit Agreement International Development Association (IDA) No. 4260-0IND tanggal 13 Pebruari 2007. (Peraturan Menteri Pertanian No: 29, 2007). Fokus utama dari program FEATI adalah fasilitasi kepada penyuluhan yang dikelola oleh pelaku utama/petani sendiri (Farmer Managed Extension Activities/FMA). Pada pendekatan FMA ini pelaku utama difasilitasi untuk merencanakan dan mengelola kebutuhan belajarnya, sehingga proses pembelajaran berlangsung efektif dan sesuai dengan kebutuhan pelaku utama.

Program FEATI sensitif gender, dimana kegiatan FMA memberikan manfaat kepada pelaku utama dan pelaku usaha, baik laki-laki maupun perempuan (Pusat Pengembangan Penyuluhan Pertanian, 2009). Kebijakan yang sensitif gender adalah kebijakan yang mencerminkan kepentingan laki-laki dan perempuan secara setara (Syaifudin, 1996). Disebutkan dalam project appraisal document $(P A D)$ dari Bank Dunia selaku fihak donor program FEATI, sedikitnya $20 \%$ dari total dana FMA diperuntukkan untuk memenuhi kebutuhan dan memberi manfaat bagi pelaku utama perempuan. Tulisan ini bertujuan untuk mengungkapkan peranan perempuan dalam implementasi program FEATI di Provinsi Jawa Tengah, khususnya di Kabupaten Magelang, yang mengintegrasikan gender.

\section{HASIL DAN PEMBAHASAN}

\section{Gender dan Ketidakadilan}

Sejarah munculnya gender dimulai dari dikumandangkannya emansipasi di tahun 1950 dan 1960-an, tahun 1975 konferensi Perserikatan Bangsa Bangsa (PBB) menghasilkan deklarasi yang yang memprioritaskan pembangunan bagi kaum perempuan (Departemen Kehutanan, 2005). Selanjutnya berkembang program pemberdayaan perempuan, dan mulai diperkenalkan tema Women In Development (WID) yang mengintegrasikan perempuan dalam pembangunan. Tahun 1980-an, berbagai studi menunjukkan bahwa kualitas kesetaraan lebih penting daripada sekedar 


\section{Dian Maharso Yuwono: Pengarusutamaan Gender Dalam Pembangunan Pertanian ...}

kuantitas, maka tema WID diubah menjadi Women and Development (WAD). Perkembangan lebih lanjut, tahun 1992 dan 1993, dipergunakan pendekatan gender yang dikenal dengan Gender and Development $(G A D)$ yang menekankan prinsip hubungan kemitraan dan keharmonisan antara perempuan dan laki-laki. Pada tahun 2000 konferensi PBB menghasilkan 'The Millenium Development Goals' (MDGs) yang mempromosikan kesetaraan gender dan pemberdayaan perempuan sebagai cara efektif untuk memerangi kemiskinan, kelaparan, dan penyakit serta menstimulasi pembangunan yang sungguh-sungguh dan berkelanjutan.

Pengertian kata gender berbeda dengan seks (jenis kelamin), dimana gender dapat berubah dari tempat ke tempat, waktu ke waktu, bahkan antar kelas sosial ekonomi masyarakat, sementara jenis kelamin dalam arti biologis tidak dapat berubah (Fakih, 1996a). Lebih lanjut Fakih (1997) menjelaskan bahwa konsep gender adalah suatu sifat yang melekat pada kaum laki-laki dan perempuan yang dikonstruksi secara sosial maupun kultural. Dengan demikian peran gender juga dapat ditukarkan antara pria dengan wanita, dapat berubah dari masa ke masa, karena pengaruh kemajuan pendidikan, teknologi, ekonomi, dan lain-lain. Perbedaan fungsi dan peran lakilaki dan perempuan itu tidak ditentukan karena diantara keduanya terdapat perbedaan biologis atau kodrat, tetapi dibedakan atau dipilah menurut kedudukan, fungsi dan peranan masing-masing dalam berbagai bidang kehidupan dan pembangunan (Handayani dan Sugiarti, 2002). Dalam kedudukan sebagai subjek pembangunan, laki-laki dan perempuan selayaknya mempunyai peranan yang sama dalam merencanakan, melaksanakan, memantau dan menikmati hasil pembangunan.

Gender menjadi permasalahan ketika timbul ketidakadilan gender (gender inequalities), yang termanifestasikan dalam bentuk marginalisasi, subordinasi, stereotipe, dan beban kerja yang lebih panjang dan lebih banyak (Fakih, 1997). Contoh marginalisasi atau proses pemiskinan perempuan dalam sektor pertanian yang sering disebutkan adalah revolusi hijau secara ekonomis telah menyingkirkan kaum perempuan dari pekerjaannya, dimana digunakan varietas unggul padi yang penampilan tanamannya lebih rendah namun produksinya lebih tinggi. Tanaman padi yang rendah mendorong pemanenan yang sebelumnya dilakukan kaum perempuan dengan menggunakan ani-ani digantikan dengan sabit. Adapun subordinasi terhadap perempuan atau anggapan tidak penting dalam membuatan keputusan, dapat dicontohkan adalah adanya anggapan bahwa perempuaan emosional sehingga menempatkan perempuan pada posisi yang tidak penting.

Stereotipe terhadap perempuan adalah penandaan atau pelabelan terhadap perempuan yang cenderung merugikan, contohnya adalah asumsi perempuan sebagai makhluk lemah sehingga tidak diberi akses maupun kontrol terhadap jenis pekerjaan yang mengandalkan kekuatan fisik. Ketidakadilan terhadap perempuan dalam bentuk beban kerja yang lebih panjang dan lebih banyak atau beban ganda dikarenakan anggapan bahwa kaum perempuan sifat memelihara dan rajin, konsekweksinya perempuan harus mengerjakan pekerjaan domestik, seperti membersihkan rumah, memasak, merawat anak dan sebagainya. Di kalangan perempuan di pedesaan terbentuk apa yang lazim disebut the develomment of dual roles (peran ganda), dimana selain sebagai tenaga kerja dalam kegiatan produksi dan dilain fihak sebagai ibu rumah tangga dengan berbagai pekerjaan domestik dalam keluarga, karena harus bertanggung jawab pada hampir semua pekerjaan yang ada di rumah dan di luar rumah terutama di sektor pertanian (Usman dalam Bainar, 1998).

\section{Pengarusutamaan Gender dalam Pembangunan Pertanian}

Upaya untuk meningkatkan peranan perempuan dan menekan kesenjangan antara laki-laki dan perempuan telah banyak dilakukan melalui berbagai kebijakan dan peraturan perundangundangan, yang pada hakekatnya menghendaki agar seluruh sumberdaya dapat dihimpun menjadi suatu kekuatan masyarakat guna mewujudkan kesejahteraan petani. Konferensi PBB tahun 2000 yang menghasilkan MDGs mendorong pemerintah Indonesia menerbitkan Inpres Nomor 9 tahun 2000 tentang Pengarusutaman Gender dalam Pembangunan Nasional yang dijabarkan dalam Program Pembangunan Nasional (Propenas) 2000-2004 


\section{Dian Maharso Yuwono: Pengarusutamaan Gender Dalam Pembangunan Pertanian ...}

(Bappenas, 2004) dan Rencana Pembangunan Tahunan (Repeta) Departemen Pertanian tahun 2004. Dalam upaya pengoptimalan pelaksanaan strategi tersebut, Pemerintah mencamtumkannya dalam Rencana Pembangunan Jangka Panjang Nasional (RPJPN) 2005-2025, yaitu menjadi salah satu arah pembangunan di dalam Misi 2 untuk mewujudkan bangsa yang berdaya saing, adalah pemberdayaan perempuan dan anak. Hal ini diwujudkan melalui peningkatan kualitas hidup perempuan, kesejahteraan perlindungan anak, penurunan kekerasan, eksploitasi dan diskriminasi serta penguatan kelembagan dan jaringan pengarusutamaan gender.

Pengarusutamaan gender (PUG) atau gender mainstreaming adalah strategi untuk mewujudkan kesetaraan dan keadilan gender dalam pembangunan, dimana aspek gender harus terintegrasi dalam perumusan kebijakan program dan kegiatan sejak perencanaan hingga evaluasi. Program PUG bertujuan agar pelaksanaan program-program pembangunan dapat mempertimbangkan kesempatan dan akses wanita terhadap program pembangunan, yaitu dengan terciptanya kendali serta manfaat bagi perempuan. Dengan demikian, diperlukan pembinaan peran petani perempuan agar mampu meningkatkan peran dan potensi mereka, terutama produktivitasnya melalui pemberdayaan mereka di segala bidang. Pengarustamaan adalah upaya/strategi yang harus dilakukan untuk memberi peluang kepada seluruh komponen atau stakeholders agar dapat berperan secara optimal dalam pembangunan. Pengarusutamaan gender merupakan sebuah upaya untuk menghilangkan hambatanhambatan yang menyebabkan ketidakadilan gender seperti marginalisiasi, sterotipe, subordinasi, dan beban ganda. Implementasti PUG dalam pembangunan pertanian, diharapkan dapat : (1) meningkatkan efektivitas dan efesiensi pemanfaatan sumberdaya pembangunan pertanian; (2) mengakselerasikan peningkatan status ekonomi dan kesejahteraan keluarga (rumah tangga tani), dan; (3) mengakselerasikan peningkatan kesejahteraan masyarakat.

\section{Peran Perempuan pada Pelaksanaan Feati di Kabupaten Magelang}

Program FEATI merupakan program 5 tahunan, secara operasional mulai dilaksanakan tahun 2008 sampai dengan tahun 2012. Provinsi Jawa Tengah sebagai salah satu dari 18 provinsi di Indonesia sebagai pelaksana program FEATI, adapun kabupaten pelaksananya meliputi Magelang, Temanggung, Batang, dan Brebes. Berdasarkan identifikasi yang dilakukan oleh pemerintah daerah, telah ditetapkan jumlah FMA pelaksana P3TIP di Provinsi Jawa Tengah sebanyak 210 FMA, terdiri atas Kabupaten Magelang 90 FMA, selebihnya Kabupaten Temanggung Batang dan Brebes masing-masing 40 FMA. Adapun fokus utama dari program FEATI adalah fasilitasi kepada penyuluhan yang dikelola oleh pelaku utama/petani sendiri (Farmer Managed Extension Activities/FMA). Pemberdayaan dan partisipatif menjadi 2 aspek penting yang menjadi fokus pada FEATI, yakni tercapainya pemberdayaan dan peningkatan kesejahteraan petani miskin merupakan target yang hendak dicapai, melalui berbagai fasilitasi agar meningkat aksesnya terhadap informasi (teknologi, pasar, jaringan usaha), meningkat pengetahuannya, dan pendapatannya semakin layak. Adapun partisipasi dicirikan dengan diberikannya kebebasan petani FMA untuk merencanakan dan mengelola sendiri kebutuhan belajarnya, sehingga proses pembelajaran berlangsung lebih efektif dan sesuai dengan kebutuhan pelaku utama dan pelaku usaha. Budiman (1991) menyatakan bahwa progam pembangunan perdesaan yang ditujukan kepada petani tanpa memperhatikan aspek pemberdayaan dan partisipasi cenderung bersifat kontradiktif.

Untuk mengukur sampai sejauh mana akses dan kontrol perempuan pada kegiatan pembelajaran yang difasilitasi FEATI menggunakan analisis gender yang paling populer terdiri atas analisis yang dikembangkan oleh para ilmuwan Studi Perempuan di Universitas Harvard, yakni analisis kegiatan (menjawab pertanyaan : siapa melakukan apa?) : (1) analisis akses dan kontrol pada sumberdaya meliputi pertanyaan: siapa mendapat sumberdaya apa? dan siapa mengontrol sumberdaya apa?; (2) analisis 
Dian Maharso Yuwono: Pengarusutamaan Gender Dalam Pembangunan Pertanian ...

manfaat, digali dengan pertanyaan: siapa memperoleh manfaat dari proyek pembangunan /kegiatan, dan; (3) analisis yang membutuhkan data kuantitatif dan kualitatif ini mampu mengungkapkan peran gender perempuan dan lelaki, serta kedudukan perempuan.

Perempuan mempunyai akses dan kontrol pada seluruh tahap pembelajaran, mulai dari perencanaan, pelaksanaan, monitoring, hingga evaluasi kegiatan pembelajaran yang dilakukan oleh masing-masing FMA di Kabupaten Magelang (Tabel 1). Perencanaan yang melibatkan perempuan diawali dengan pelaksanaan participatory rural appraisal
(PRA) yang ditindaklanjuti dengan penyusunan proposal kegiatan pembelajaran. Hal ini dimungkinkan karena perempuan mendapatkan kesempatan yang sama untuk menjadi Unit Pengelola-FMA (UP-FMA) yang ditetapkan secara demokratis, dimana struktur organisasi UP-FMA terdiri atas ketua, sekretaris, bendahara, dan penyuluh pertanian swadaya (PP swadaya). Komitmen FEATI terhadap PUG juga diindikasikan dari ditetapkannya pada masing-masing FMA terdapat 2 orang PP swadaya, terdiri atas 1 orang laki-laki dan 1 orang perempuan.

Tabel 1. Akses dan Kontrol Laki-laki dan Perempuan pada Pelaksanaan Program FEATI di Kabupaten Magelang Tahun 2011

\begin{tabular}{lcccc}
\hline \multirow{2}{*}{ Kegiatan } & \multicolumn{2}{c}{ Akses } & \multicolumn{2}{c}{ Kontrol } \\
\cline { 2 - 5 } & Laki-laki & Perempuan & Laki-laki & Perempuan \\
\hline Perencanaan & Ya & Ya & Ya & Ya \\
Pelaksanaan & Ya & Ya & Ya & Ya \\
Monitoring & Ya & Ya & Ya & Ya \\
Evaluasi & Ya & Ya & Ya & Ya \\
\hline
\end{tabular}

Sumber : Badan Pelaksana Penyuluhan dan Ketahanan Pangan (BP2KP)

Kabupaten Magelang, 2011

Tabel 2. Jumlah Ppeserta Pembelajaran Laki-laki dan Perempuan pada Pelaksanaan Program FEATI di Kabupaten Magelang Tahun 2011

\begin{tabular}{|c|c|c|c|c|c|c|c|}
\hline \multirow[t]{2}{*}{ No } & \multirow{2}{*}{ Kecamatan } & \multirow{2}{*}{$\begin{array}{c}\text { Jumlah } \\
\text { desa }\end{array}$} & \multirow{2}{*}{$\begin{array}{l}\text { Jumlah } \\
\text { peserta } \\
\text { (orang) }\end{array}$} & \multicolumn{2}{|c|}{ Laki-laki } & \multicolumn{2}{|c|}{ Perempuan } \\
\hline & & & & Orang & $\%$ & Orang & $\%$ \\
\hline 1. & Bandongan & 6 & 258 & 205 & 79,46 & 53 & 20,54 \\
\hline 2. & Borobudur & 10 & 322 & 281 & 87,27 & 41 & 12,73 \\
\hline 3. & Candimulyo & 5 & 143 & 119 & 83,22 & 24 & 16,78 \\
\hline 4. & Dukun & 4 & 144 & 136 & 94,44 & 8 & 5,56 \\
\hline 5. & Grabag & 7 & 215 & 181 & 84,19 & 34 & 15,81 \\
\hline 6. & Kajoran & 11 & 265 & 224 & 84,53 & 41 & 15,47 \\
\hline 7. & Kaliangkrik & 9 & 333 & 257 & 77,18 & 76 & 22,82 \\
\hline 8. & Mungkid & 3 & 96 & 94 & 97,92 & 2 & 2,08 \\
\hline 9. & Ngablak & 4 & 153 & 134 & 87,58 & 19 & 12,42 \\
\hline 10. & Salaman & 5 & 215 & 208 & 96,74 & 7 & 3,26 \\
\hline 11. & Sawangan & 4 & 170 & 106 & 62,35 & 64 & 37,65 \\
\hline 12. & Secang & 7 & 244 & 202 & 82,79 & 42 & 17,21 \\
\hline 13. & Tegalrejo & 4 & 165 & 147 & 89,09 & 18 & 10,91 \\
\hline 14. & Tempuran & 4 & 80 & 65 & 81,25 & 15 & 18,75 \\
\hline \multirow[t]{3}{*}{15.} & Windusari & 7 & 417 & 365 & 87,53 & 52 & 12,47 \\
\hline & Jumlah & 90 & 3.220 & 2.724 & - & 496 & - \\
\hline & Rata-rata & - & - & - & 84,60 & - & 15,40 \\
\hline
\end{tabular}

Sumber : Badan Pelaksana Penyuluhan dan Ketahanan Pangan (BP2KP) Kabupaten Magelang, 2011 


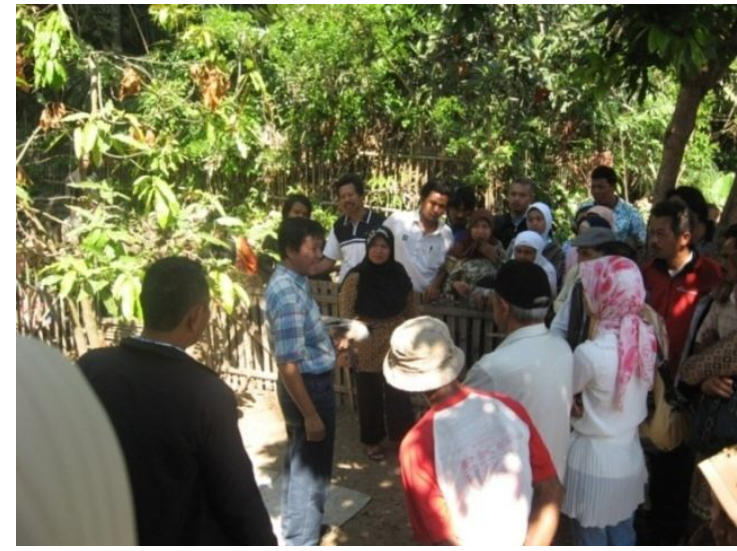

Sumber : D.M. Yuwono, koleksi pribadi

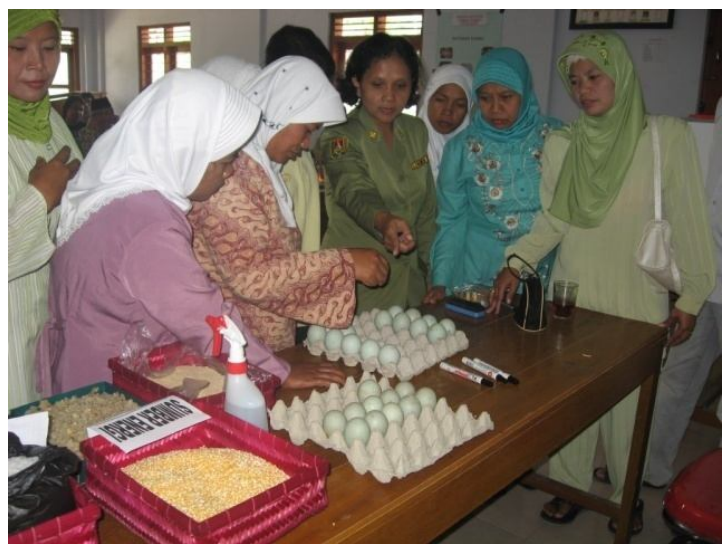

Gambar 1. Keterlibatan Perempuan pada Pelatihan Budidaya Itik di FMA Desa Pagersari, Kecamatan Mungkid, Kabupaten Magelang

Hal ini sejalan dengan yang disampaikan Hastuti (2004b) dimana partisipasi perempuan di dalam kelembagaan di tingkat lokal relatif tinggi, antara lain disebabkan tidak terdapat perbedaan status sosial ekonomi diantara para anggota, dan pada umumnya kelembagaan lokal terbentuk secara otonom sesuai dengan kebutuhan masyarakat.

Contoh peran perempuan dalam pembelajaran agribisnis diantaranya adalah pada FMA Desa Pagersari, Kecamatan Mungkid, Kabupaten Magelang, yang mengadakan pembelajaran budidaya itik secara terkurung. Bu Hartini yang pada tahun 2008 ditunjuk menjadi Ketua FMA mampu mengadopsi teknologi hasil pembelajaran dan dalam perkembangannya telah tumbuh kelompok usaha bersama (KUB) yang anggotanya 18 orang perempuan petani yang menempatkan itik pada kandang kelompok. Cabang usaha yang berkembang meliputi budidaya itik untuk memproduksi telur tetas, usaha penetasan telur itik dan usaha pengolahan telur dan itik afkir.

Tabel 2 menunjukkan jumlah peserta pembelajaran laki-laki dan perempuan pada pelaksanaan program FEATI di Kabupaten Magelang tahun 2011. Dari jumlah tersebut terlihat bahwa persentase rata-rata peserta pembelajaran perempuan sebesar $15,40 \%$, lebih rendah dibanding yang disebutkan dalam project appraisal document (PAD) dari Bank Dunia selaku fihak donor program FEATI, dimana sedikitnya 20\% dari total dana FMA diperuntukkan untuk memenuhi kebutuhan dan memberi manfaat bagi pelaku utama perempuan. Kondisi ini diduga karena masih adanya peran ganda di kalangan petani perempuan. Kegiatan pembelajaran terutama dalam bentuk pelatihan secara klasikal yang menyita waktu cukup panjang menyebabkan tidak banyak petani perempuan yang terdaftar secara administrasi sebagai peserta. Meskipun demikian, keterlibatan langsung tenaga kerja perempuan pada kegiatan pembelajaran agribisnis diduga lebih tinggi. Seperti yang disampaikan oleh Ibu Riyati anggota pembelajaran pada FMA Desa Jogonayan, Kecamatan Ngablak, Kabupaten Magelang, bahwa untuk mengikuti pelatihan secara klasikal terkendala oleh pekerjaan domestik, namun keterlibatan petani perempuan dalam usahatani sangat dominan.

\section{SIMPULAN}

Program FEATI di Kabupaten Magelang sebagai salah satu contoh bentuk pengarusutamaan gender (PUG) pada pembangunan pertanian, dimana dalam implementasinya mendorong perempuan mempunyai akses dan kontrol pada seluruh tahap pembelajaran, mulai dari perencanaan, pelaksanaan, monitoring, hingga evaluasi kegiatan pembelajaran yang dilakukan oleh masing-masing FMA. Hal ini dimungkinkan karena perempuan mendapatkan kesempatan yang sama baik selaku pengurus UP-FMA maupun anggota FMA. Komitmen FEATI terhadap PUG juga diindikasikan keberadaan 


\section{Dian Maharso Yuwono: Pengarusutamaan Gender Dalam Pembangunan Pertanian ...}

penyuluh pertanian swadaya di masing-masing FMA. Adanya peran ganda petani perempuan menyebabkan persentase peserta pembelajaran dari kalangan perempuan masih lebih rendah dibanding yang ditetapkan Bank Dunia, yakni $20 \%$, meskipun secara riil keterlibatan perempuan dalam pengembelajaran agribisnis persentasenya diduga lebih besar dari angka tersebut.

\section{DAFTAR PUSTAKA}

Badan Pengembangan Sumberdaya Manusia Pertanian. 2007. Pedoman Pengelolaan Program P3TIP/FEATI. Badan Pengembangan Sumberdaya Manusia Pertanian - Departemen Pertanian.

Badan Pelaksana Penyuluhan dan Ketahanan Pangan (BP2KP) Kabupaten Magelang. 2011. Laporan Tahunan Kegiatan FEATI/P3TIP Kabupaten Magelang Tahun 2011.

Bainar. 1998. Wacana Perempuan dalam Keindonesiaan dan Kemodernan. CIDES dan Universitas Islam Indonesia. Yogyakarta.

Bappenas. 2007. Rencana Pembangunan Jangka Panjang Nasional (RPJPN) 20052025. www.bappenas.go.id/get-fileserver/node/3374/

Bappenas. 2008. Program Pembangunan Nasional 2000-2004 (PROPENAS). http://www.bappenas.go.id/node/42/320/ program-pembangunan-nasional-20002004-propenas

Budiman, A. 1991. Model Pembangunan Teknokrat kita. Yayasan Paramadina dan LP3ES. Jakarta.

Departemen Kehutanan, 2005. Laporan tahunan kegiatan pengarusutamaan gender. http://ebookbrowse.com/laporantahunan-kegiatan-pengarusutamaangender-tahun-2005-pdf-d17580784

Fakih, M. 1996a. Gender sebagai Alat Analisis Sosial; dalam : Analisis Gender dalam Memahami Persoalan Perempuan. Jurnal Analisis Sosial. Edisi 4 November 1996.
Fakih, M. 1997. Analisis Gender dan Transformasi Sosial. Pustaka Pelajar. Yogyakarta. Cetakan Kedua.

Handayani, Trisakti dan Sugiarti. 2002. Konsep dan Penelitian Gender. Universitas Muhammadiyah Malang: Jawa Timur.

Hastuti. E.L. 2004a. Hambatan Sosial Budaya dalam Pengarusutamaan Gender di Indonesia (Socio-Cultural Constraints on Gender Mainstreaming in Indonesia). http://pse.litbang.deptan.go.id/ind/pdffile s/WP_50_2004.pdf

Hastuti, E.L. 2004b. Pemberdayaan petani dan kelembagaan Lokal dalam Perspektif Gender. Working Paper. Pusat Penelitian dan Pengembangan Sosial Ekonomi Pertanian.

Hesti, R. W. 2012. Identifikasi kebutuhan teknologi pertanian dalam usaha pertanian semi-arid menurut perspektip petani perempuan: tantangan bagi peneliti. http://hartappleng.blogspot.com/ 2012/04/identifikasi-kebutuhanteknologi.html

Instruksi Presiden No. 9 Tahun 2000 tentang Pengarusutamaan Gender dalam Pembangunan Nasional.

Kantor Menteri Negara Peranan Wanita. 1998. Gender dan Permasalahannya. Modul Pelatihan Analisis Gender. Kantor Menteri Negara Peranan Wanita. Jakarta.

Mulyadi, Agus, Wahyuni, S. Rachmawati, S. Silitonga S, Sukarsih, dan Suparyanto, A. 1993. Peranan Perempuan dalam System Usaha tani di Jawa dan Bali. Proyek Pembangunan Penelitian Pertanian Nasional Bekerjasama dengan Pusat Penelitian dan Pengem-bangan Peternakan. Badan Pene-litian dan Pengembangan Pertanian. Bogor.

Peraturan Menteri Pertanian No: 29/Permentan/ OT.140/3/2007 tentang Organisasi dan Tata Kerja Program Pemberdayaan Petani melalui Teknologi dan Informasi Pertanian.

Pusat Pengembangan Penyuluhan Pertanian. 2009. Pedoman Pelaksanaan Kegiatan Penyuluhan yang Dikelola oleh Petani 
Dian Maharso Yuwono: Pengarusutamaan Gender Dalam Pembangunan Pertanian ...

Desa (Farmers Managed Extension Activities/FMA).

Safar, M. 2006. Diferensiasi peran gender dan pengaruh budaya dalam aktivitas pertanian di perdesaan, Studi di Kecamatan Pondidaha Kabupaten Konawe Provinsi Sulawesi Tenggara. Selami IPS. Edisi Nomor 19 Vol I Tahun XI Desember 2006.

Sajogyo, P. 1984. Peranan Wanita dalam Perkembangan Ekonomi. Yayasan Obor Indonesia. Jakarta.

Sjaifudin, H. 1996. Sensitifitas Gender dalam Perumusan Kebijakan Publik. Jurnal Analisis Sosial. Edisi 4, November 1996.
Soemartoyo, S.R. 2002. Pemberdayaan Perempuan di Indonesia dan Peluang Untuk Pemberdayaan Ekonomi Perempuan. Disampaikan oleh Menteri Pemberdayaan Perempuan pada The ACT Seminar and Summit. Japan-Indonesia: Dinamic Relationship for Regional Development.

Wahyuni, Ekawati S. 2007. Perempuan petani dan penanggulangan kemiskinan. Agrimedia. Volume 12 Nomor 1.

Wijaya. 1993. "Sumber Daya yang Terabaikan: Perempuan Tani dalam Penyuluhan Pertanian". Masyarakat IndonesiaNo.2. 